\title{
Survival analysis and iniquities in older Brazilians: a six year follow up survey in São Paulo, Brazil
}

\author{
Jair LF Santos ${ }^{1 *}$, Maria Lúcia Lebrão², Yeda AO Duarte ${ }^{3}$ \\ From International Society for Equity in Health: 6th International Conference 2011 \\ Cartegena, Colombia. 26-28 September 2011
}

\section{Background}

In Brazil, the aging process is fast with consequences for health services. By 2025 the elders will be more than 30 million people, $15 \%$ of Brazilian population. This study analyzes inequalities associated with survival of elders in a six year follow-up in Sao Paulo, Brazil.

\section{Methods}

Data comes from a longitudinal survey - SABE Study (Health, Well Being and Aging) that began in 2000 with a sample of population aged 60+ living in São Paulo/Brazil $(\mathrm{n}=2,143$ from a multi stage clustered sampling). A procedure with probability proportional to the size was carried out using census tracts with replacement. To achieve the desired oversampling for respondents aged $75+$, additional households close to the selected census tracts were sampled. The second wave was done in 2006 when 1115 elders were re-interviewed. Descriptive statistics included tests for association using Rao Scott procedure with correction for sample-design. Multi variable analysis was done by adjusting Cox regressions with robust estimation, stratified by age and sex. Kaplan-Meier Survival Analysis was used to compare survival curves by social demographic conditions (sex, schooling, income, early conditions) and health (depression, comorbidities, disability, self-perceived health and falls).

\section{Results}

Mortality rate was 55.2/1000years for males and 34.0/ $1000 y e a r s$ for females. The demographic variables associated with survival, besides age and gender, were: greater education $(\mathrm{p}<0.0000)$, higher income $(\mathrm{p}<0.0000)$ and urban origin for women $(\mathrm{p}=0.015)$. The health related variables were self-reported better health $(\mathrm{p}<0.000$ for women and $\mathrm{p}=0.016$ for men), no self-reported disease $(\mathrm{p}<0.000)$, depression ( $\mathrm{p}=0.035$ for women) and no disability $(p<0.000)$. Cox regression showed clearly a gradient of increasing mortality with the decrease in income. In Kaplan-Meier analysis, absence of disability makes the male curve higher than the female.

\section{Conclusions}

There are inequalities associated with lower survival. Public policies should take into account the needs of the elderly population to facilitate access to health care services and reduce inequities.

\section{Acknowledgements}

Maria Lucia Lebrão is the Coordinator of the SABE study. Jair LF Santos and Yeda AO Duarte receive support from National Council of Research (CNPq). The SABE study is supported by The São Paulo Research Foundation (FAPESP).

\section{Author details}

'Department of Social Medicine, University of São Paulo, São Paulo, Brazil. ${ }^{2}$ Department of Epidemiology, University of São Paulo, São Paulo, Brazil. ${ }^{3}$ Department of Nursing Medical Surgery, University of São Paulo, São Paulo, Brazil.

Published: 23 January 2012

doi:10.1186/1475-9276-11-S1-A8

Cite this article as: Santos et al:: Survival analysis and iniquities in older Brazilians: a six year follow up survey in São Paulo, Brazil. International Journal for Equity in Health 2012 11(Suppl 1):A8. 